\title{
A Case Study Study on methodology for estimation of lac production in India
}

\section{GOVIND PAL}

\section{Correspondence to :}

\section{GOVIND PAL}

Directorate of Seed Research (ICAR),

Kushmaur, MAU (U.P.) INDIA

Email: drpal_1975@ scientist.com

Paper History :

Received : 25.11.2014;

Accepted : 23.02.2015

\begin{abstract}
Estimation of lac production is required by the Government, lac-based industries, lac traders, exporters and importers and with the timely and accurate estimation of lac production they can plan their operations in time. The objective of present study is to develop methodology for estimation of lac production and processing at national level. The approach used in the present methodology was based on primary data and information. The study is conducted during the year 2006-07 to 2011-12. All lac produced in India moved through the lac markets/ lac traders. Survey of all big lac traders was helpful in estimation of lac production. As big lac traders are limited in number and they have close contact with the primary purchaser of lac who have knowledge of present crop condition and expected output. Further, all lac produced moved through the lac processing units. Survey of lac processing units was also helpful in estimating quantity of lac processed at national level and validation of lac production data. Five questionnaires were framed for collection of data and information during the field surveys. Lac production year in present study was April to March. Data and information for estimation of lac production and processing was collected throughout the year. Lac producing states have been classified in two group i.e. major lac producing states and minor lac producing states. Total 56 lac markets in major lac producing states and 11 lac markets in minor lac producing states have been identified for survey work. All twenty two lac processing centers/ secondary markets existing in the country was surveyed. Tabular analysis was used to analyze the survey data. Validation of lac production data at national level has been made by quantity of lac processed at national level, export and import.
\end{abstract}

KEY WORDS : Lac, Estimation, Production, Processing

HOW TO CITE THIS PAPER : Pal, Govind (2015). Study on methodology for estimation of lac production in India. Internat. Res. J. Agric. Eco. \& Stat., 6 (1) : 205-209. 